\title{
Introducing Web 2.0: social networking and social bookmarking for health librarians
}

\author{
Eugene Barsky and Michelle Purdon
}

In this last article in our series [1,2] introducing Web 2.0 applications to Canadian health librarians for the Journal of the Canadian Health Libraries Association, we would like to sum up Web 1.0 and Web 2.0 this way: Web 1.0 was almost all about commerce; Web 2.0 is almost all about people.

Web 2.0 is about the architecture of participation. Using Web 2.0 applications, we provide a service, not a product. We encourage user contribution, we create collective intelligence, we make it easy to reuse and remix content, we focus on customer self-service, and finally we create a feeling of belonging to a community, as well as a sense of empowerment and ownership.

Web 2.0 is about democracy. By now we have several examples that prove even amateurs can surpass professionals, when they have the right kind of system and tools to channel their efforts. Of these, Wikipedia (http://wikipedia.org) is certainly the most well-known example. Experts have given Wikipedia mixed reviews, but we believe they miss the critical point - that it's good enough for people to use and that it facilitates use. And it's free, which means people can actually read it, and they do - daily, in droves. The most dramatic example of Web 2.0 democracy is not in the selection of ideas but in their production. Have you ever noticed that content you read on individual blogs is as good as or better than the content you usually read in newspapers and magazines?

We believe that Web 2.0 is not only about a crowd of geeks paying US\$2800 per person to attend the sold-out 2005 Web 2.0 Conference in San Francisco, where 800 people jostled in the doorways of sessions and workshops. It is about us - users generating content, rather than simply consuming it. And it is about open programming interfaces that allow everybody to participate.

Looking at the recent Web 2.0 Awards (http://web2.0awards.org), therefore, we feel very proud. At the Irving K. Barber Learning Centre at the University of British Columbia Library, where one of this article's authors hails from, we use many of the award-winning applications to serve our clients' information

E. Barsky. ${ }^{1}$ Irving K. Barber Learning Centre, University of British Columbia, 1961 East Mall, Vancouver, BC V6T 1Z1, Canada.

M. Purdon. Strategic Health Information \& Planning Services (SHIPS), SHR Medical Library, 701 Queen Street, Saskatoon, SK S7M 0M7, Canada.

${ }^{1}$ Corresponding author (e-mail: eugene.barsky@ubc.ca; blog: http://weblogs.elearning.ubc.ca/physio/). needs. We use Bloglines (http://bloglines.com) to subscribe to relevant really simple syndication (RSS) feeds in our areas of interest. We use PubSub (http://pubsub.com) to search future content appearing on our topics of interest and convert it to RSS feeds for future use. We use Furl (http://furl.net) for Web site social bookmarking. We share photos and make notes about them on Flickr (http://www.flickr.com). We use Odeo (http://www.odeo.com) to record and share simple podcasts. We create discussion groups for our clients on MySpace (http://www.myspace.com). We use Rollyo (http://rollyo.com) to create specialized search engines. Moreover, we blog, read RSS feeds, and share content, and yes, we are still alive and have some time for fun. In this article, we will follow the theme of the excellent Canadian Health Libraries Association / Association des bibliothèques de la santé du Canada 2006 Conference in Vancouver and share with you some pearls we have come to know about social networks and social bookmarking and folksonomies.

\section{Social networks}

So what's the buzz about social networks? Or more to the point, what exactly are online social networks? Well, we see these as relatively new kinds of virtual communities that are structured to delineate and build on relationships that members have with each other by virtue of their being part of that community.

Informal social networking has existed since the inception of the Web, but sites dedicated to social networking have been expanding exponentially since 2003 . These sites collect data about members and then store this information as user profiles. The data, or profiles, can then be shared among the members of the site. Social network sites offer a free and easy way to create personal Web pages and fill them with content such as blogs, digital photographs, favourite music, short video clips, and much more. Social networks are formed as members link their Web pages to those of their friends and search through the vast number of sites in search of new friends who might share common interests.

Membership on social networking sites has become ubiquitous. MySpace.com is one of the most popular sites on the Internet (second only to Yahoo in the number of page views per day), boasting more than 80 million members who collectively host more than 16 million Web sites. This is two or three times the traffic on Google per day! For its part, Facebook.com is currently rated as the top site for 18-to-24- 
year-olds, with more than 7.5 million members. These are astounding numbers, considering that both MySpace and Facebook were each launched just over 2 years ago.

While MySpace.com and Facebook.com are US-based sites, the social networking phenomenon is an international one. In South Korea, Cyworld.com is threatening to swallow the country. Less than 4 years after its launch, 15 million people - the equivalent of almost a third of South Korea's population - are Cyworld members. Among those in their late teens and early twenties, $90 \%$ are hooked. So as you can see, these social network Web sites are extremely popular, particularly with teens and young adults. Some of the more popular social network Web sites include the following:

(i) MySpace (http://www.myspace.com) - Currently, it is the world's fourth most popular English-language Web site and the fifth most popular in the world. MySpace can play and store music (http://music.myspace.com) and also offers powerful invitation management capabilities. MySpace was purchased in 2005 by media pioneer Rupert Murdoch for over US\$580 million.

(ii) Facebook (http://facebook.com) - Facebook allows membership only for people with e-mail accounts ending in ".edu" (denoting US college and university accounts), although membership was recently expanded to include high school students. Uniquely, Facebook's online communities are organized by campus, and it is estimated that about $85 \%$ of students in supported institutions have a profile on Facebook.

(iii) Friendster (http://www.friendster.com) - Friendster was one of the first sites to allow users to create personal profile pages online, post photos, and link to other friends. It grew quickly for a while, but its servers couldn't handle the heavy traffic, and its popularity has since declined.

So how can you use these resources in your everyday practice, you may ask at this point? Well, we see a number of ways that our community might use these tools. Our personal belief is that our work is very much about communities, and increasingly, not only in the sense of the geographic area of the building (i.e., the library) but also in the way that we share knowledge with our clients and each other. We can use these tools to assist our clientele to share information with each other. By creating discussion groups and communities of practice (COPs) on MySpace or similar resources, we can meet some of the information needs of the health professionals we work with. For instance, this summer, one of the coauthors of this paper created a neurological physiotherapy discussion group for his clients who wanted to discuss treatment of neurological injuries. Librarians working with the general public might also consider recommending or even setting up support groups for a particular condition or a disease, like the MySpace "Cure Diabetes" group (http://groups.myspace.com/cureDiABETES).

Specifically geared for use in the library environment is LibraryThing (http://www.librarything.com/). This is a library social network site and a place for members to register the books they have read, will read, or are in the process of reading. But it is also much more. LibraryThing promotes social interactions, book recommendations, self-classification, and monitoring of new books. It's certainly worth a try!

\section{Social bookmarking and folksonomies}

Social bookmarking tools appeared at about the same time as social networks and have created quite a stir in their own right. Wikipedia defines social bookmarking as the practice of "classifying resources by the use of informally assigned, user-defined keywords or tags" (http://en.wikipedia.org/wiki/ Social_bookmarking). In essence, users can collect their favourite resources in an online, open environment, which others are free to read and use. The end result is the sharing of resources and the easy distribution of those resources. While many are just starting to be noticed, there are a couple of tools that could be of particular interest:

(i) Delicious (http://del.icio.us/) is an interesting site that allows anyone to place their favourite links onto their own page within the Delicious domain. After a simple sign-up procedure, users can easily start adding Web sites to their account. Once a user chooses a site to bookmark, the URL, description, "extended", and "tags" information can be provided. At this time, both the extended and tags sections are optional. The extended section of the bookmark allows the user to annotate the sites. This is useful because Delicious also offers a search feature that allows users to search their own bookmarks. What makes Delicious worth using as a community-based tool, however, is the tags section. For each bookmark, users can assign tags. Once that tag is placed, a separate URL will be created for any new bookmarks that are given that tag, no matter who bookmarked it. This is where the community and sharing features come in. Any Web site posted on Delicious that has the same tag in it will be placed on that particular URL. For instance, the Google Scholar URL on Delicious lists all sites that were assigned to this category by different people (http://del.icio.us/tag/google_scholar).

(ii) Furl (www.furl.net) is another free online bookmarking tool that allows users to easily post and annotate Web sites. Each post can be placed into categories via the posting options, and these are displayed within the Furl URL that is created.

Social bookmarking tools are excellent resource discovery tools; when searching for a particular subject, you may see that other users tagged a particular Web page and other sites under similar tags. This allows you to see the collective list of resources from all the users who share the same research interest. The advantages of social bookmarking utilities are apparent; these tools are Web-based and searchable, and they facilitate the development of communities of interest and expertise.

It is important to remember, however, that social tagging tools — folksonomies — are built from the bottom up; they are built by people like you and us. They are democratic and inclusive, but as such they provide a snapshot of current users' behaviour and preferences, and they are not stable or controlled. For example, a look at the popular tags list on Furl gives you immediate insight into what users are working on right now (http://www.furl.net/furledPopular.jsp).

Again, how might we as librarians use these relatively new tools in our practice? Well, we can use social bookmarking tools to create Internet subject guides. An example of this is the University of Pennsylvania Library's so- 
cial tagging cloud (frequently used tags appear in larger fonts) (http://tags.library.upenn.edu/). This page provides up-to-the-date information on user behaviour at the university's library. Moreover, how about tagging your own online public access catalog (OPAC)? No, we are not suggesting removing the traditional subject taxonomies but rather just enhancing these by allowing users to tag their favourite materials and allowing other people, in turn, to use their tags.

Please do remember though that folksonomies and tagging are in their infancies. New features are constantly popping up. More than ever, this is a time of experimentation and rapid development, but don't we all love change? This is yet another, extremely interesting trend to watch and experiment with.
To conclude, we want to encourage you to use some of the Web 2.0 applications. Play around, try new things, and see if they work for you and for your institution. Many won't work or won't be appropriate, but don't be afraid to drop them and try something else. Almost all Web 2.0 applications are free, friendly, and easy to use. They are worth a try. Have fun!

\section{References}

1. Barsky E. Introducing Web 2.0: RSS trends for health librarians. J Can Health Libr Assoc. 2006;27(1):7-8.

2. Barsky E. Introducing Web 2.0: weblogs and podcasting for health librarians. J Can Health Libr Assoc. 2006;27(2):33-4. 
This article has been cited by:

1. Dean Giustini, Daniel Hooker, Allan Cho. 2009. Social cataloguing: an overview for health librarians. Journal of the Canadian Health Libraries Association 30:4, 133-138. [Citation] [PDF] [PDF Plus]

2. Eugene Barsky, Dean Giustini. 2007. Introducing Web 2.0: wikis for health librarians. Journal of the Canadian Health Libraries Association 28:4, 147-150. [Abstract] [PDF] [PDF Plus]

3. Eugene Barsky, Allan Cho. 2007. Introducing Web 2.0: social search for health librarians. Journal of the Canadian Health Libraries Association 28:2, 59-61. [Abstract] [PDF] [PDF Plus]

4. Allan Cho. 2007. An introduction to mashups for health librarians. Journal of the Canadian Health Libraries Association 28:1, 19-22. [Citation] [PDF] [PDF Plus] 